\title{
Editorial
}

\section{Qualidade, pertinência, relevância, responsabilidade social, bem público}

Quality, pertinence, relevance, social responsibility, public good

\author{
José Dias Sobrinho ${ }^{1}$ \\ ${ }^{1}$ Professor titular aposentado da Unicamp
}

DOI: http://dx.doi.org/ 10.1590/S1414-40772019000100001

Este é um artigo publicado em acesso aberto sob uma licença Creative Commons https://creativecommons.org/licenses/by-nc/4.0/

O título indica as rápidas reflexões que se vão seguir. São palavras ampla e globalmente utilizadas sem muita preocupação com os seus significados e usos, como se fossem termos autoevidentes, isto é, como se não precisassem de explicações, conceituações, contextos de uso, transformações. É como se tivessem significados unívocos, pétreos, imutáveis. É como se não houvesse pluralismo, divergências e contradições na sociedade.

Discuti-los é tarefa complicada e até mesmo complexa, sempre lacunar, inevitavelmente ideológica e carregada de interesses e posições políticas de quem se arrisca a (re)pensá-los. Mas, por serem palavras cheias de pesadas ideias e importantes consequências, não devem passar incólumes, protegidas por pretensa neutralidade e suposta autoevidência. Tudo o que é social, como a política, a economia, a educação, a cultura, a ciência, as relações humanas em geral, é atravessado de ideologias e contradições. Não fosse ideológico e movido por interesses não seria humano. Não fosse constituído por contradições e conflitos não seria social. Negar a ideologia na vida social e pública já é adotar uma ideologia. Talvez, a pior delas.

Nenhum dos termos do título deste pequeno ensaio pode ser pensado isoladamente. É um conjunto inextricavelmente inter-relacionado e interdependente. Pode-se chamá-los de coessenciais. Um não existe sem o outro. O que mais propriamente permite explicitar um pouco de cada um são as relações complexas que se estabelecem entre eles. É o caráter de bem público que exige pertinência, relevância e responsabilidade social.

Num capítulo de um livro publicado pela Unesco (2009), eu já alertava para a necessidade de interligar os conceitos de qualidade, relevância (e pertinência), equidade, 
responsabilidade social, diversidade cultural e os contextos em que isso é estabelecido. No caso da educação superior, afirmei que o conceito de qualidade precisa levar em consideração os compromissos públicos e os papeis das instituições e do Estado, tendo em vista as necessidades do conjunto da sociedade (DIAS SOBRINHO, 2009, p.100).

Em continuação, afirmava no texto que uma distinção fundamental devia ser claramente estabelecida. Trata-se da distinção entre os conceitos de qualidade próprios dos setores industriais e demais atividades da economia, amplamente vigentes e invasivos, e, de outro lado, os conceitos de qualidade ínsitos na educação. Das corporações de caráter econômico a educação acolheu, em grande parte, o conceito de qualidade associado a eficiência, produtividade, custo-benefício, adequação às necessidades da indústria e do mundo do trabalho, empregabilidade, números e quantidades de estudantes e de publicações etc. Segundo essa lógica, a qualidade é mensurável e deve ser disposta aos stakeholders e ao público em geral, de forma simplificada e objetiva, por meio de números, estatísticas, quantidades.

Uma empresa é autorreferente. Basta-lhe executar eficazmente seus meios, cumprir adequadamente os objetivos de seu desenvolvimento e aumento de lucros. Em uma empresa, a gestão, o planejamento, a produtividade, a competição e o lucro são valores em si mesmos (FREITAG, 1995, p. 32). Pouco lhe importa a vida das pessoas. Quem não produz, quem não aumenta os ganhos das empresas, geralmente é excluído, mediante diferentes formas de negação e invisibilidade: jurídicas, socioeconômicas, culturais, educativas, epistemológicas. (MUÑOZ, 2008, p. 245).

É indiscutivelmente desejável que a economia de um país seja forte, haja empregos condignos à população, os implicados nas atividades de produção sejam bem formados etc. A educação, especialmente a de nível superior, tem enormes responsabilidades na formação de profissionais competentes e capacitados. O Estado atribui à educação, com razão, um dos papeis mais importantes para o desenvolvimento da economia. Tudo isso faz parte dos legítimos interesses da sociedade. Contudo, as finalidades essenciais da educação, do conhecimento, da formação, são muito maiores e mais complexas que essas funções pragmáticas. A economia não deve determinar a sociedade. O contrário deveria ser o verdadeiro. A qualidade em termos empresariais contém apenas parte do sentido pleno dessa palavra. Diferentemente do meio empresarial e corporativo, a referência da educação é a sociedade. A educação é pública, isto é, patrimônio e responsabilidade de todos. Portanto, "pertenece a los âmbitos de los derechos sociales y de la solidaridad, es decir, de la responsabilidad colectiva." (DIAS SOBRINHO, 2008, p. 137). Daí que não deve ser a economia que há de induzir os conteúdos da formação. Por isso mesmo, não pode ser excludente, alimentar a rivalidade. Cumpre-lhe a formação de 
cidadãos conscientes, éticos, solidários e cultos, munidos de valores, conhecimentos e técnicas propícias ao aumento do bem-estar e da dignidade pessoal, à elevação da sociedade e à construção da nação. O humano é maior e mais complexo.

A qualidade da educação, essencial, insubstituível e irredutivelmente, está integrada nos processos gerais de socialização, do fortalecimento da cidadania, das estruturas críticas, intelectuais, éticas, culturais, de responsabilidade pública no desenvolvimento pessoal e na edificação de uma nação justa, solidária e radicalmente democrática.

O Estado tem o dever de fomentar a economia, por todos os meios e recursos materiais e humanos. Mas isso é só uma parte de suas obrigações. A economia não é fim, não é o horizonte último a ser erigido. É a base da sobrevivência, é o grande sistema de organizar a vida humana. Portanto, também é fundamental e deve ser seriamente fomentado pelo Estado e pela sociedade. Mas as obrigações do Estado vão muito além disso. A ele compete criar as condições materiais e humanas para a formação de cidadãos cultos, autônomos e socialmente responsáveis, participantes ativos e conscientes do esforço de construção da nacionalidade, capazes de compreender as transformações vertiginosas da globalização e de formular grandes sínteses a respeito dos caminhos da humanidade. Aí está o sentido profundo da educação. De acordo com essa linha de pensamento, cabe ao Estado reforçar o sentido público da educação, com equidade e justiça social. Compete às instituições educativas o exercício permanente da responsabilidade pública, em aliança com o Estado e com a sociedade, embora não totalmente harmonioso e sem as múltiplas contradições.

Em termos conexos, as atividades e os produtos da educação superior hão de ser pertinentes e relevantes, isto é, atender às principais e mais urgentes necessidades sociais e contribuir eficaz e rigorosamente para o desenvolvimento cultural da população e as exigências do campo do complexo ciência-tecnologia-inovação. Mas nada disso valerá a pena se não houver equidade ou justiça social, a começar pela inclusão de indivíduos e setores sociais historicamente marginalizados. A qualidade da educação só pode ser completa se buscar a universalização e a permanência de estudantes, na medida de suas competências e possibilidades. Não basta incluir. É preciso oferecer as melhores condições para que os incluídos, até então marginalizados, tenham as condições básicas, pessoais e estruturais, para frequentarem as salas de aula e laboratórios. Quanto mais fragilizados socialmente, mais merecem atenções das instituições para que possam permanecer nos cursos usufruindo dignamente da qualidade de ensino e pesquisa que se oferecem aos mais favorecidos pela sociedade. A qualidade não pode ser elitista, nem atender exclusivamente a critérios e necessidades que não tenham pertinência social e relevância científica. 
No texto acima citado, afirmei:

If the criteria of equity and social justice that are associated with the concept of education as a public good are taken into account, then it must be concluded that an education system that excludes certain groups or, as is often the case, most of the national population, is not a quality system. (DIAS SOBRINHO, 2009, p. 102.)

Ter pertinência significa dar respostas possíveis às demandas do entorno e da nação. É fazer com que as atividades de ensino, pesquisa, publicação e serviços tenham utilidade pública e se comprometam com a solução possível das mais urgentes prioridades da comunidade de entorno e/ou da sociedade nacional. A instituição educativa não é a única responsável pela sociedade, longe disso, mas lhe compete assumir seu papel na melhoria das condições de vida da população mais necessitada, de acordo com a missão que a ela se atribui e considerando os seus limites e suas contradições. Para isso, precisa ensinar e produzir conhecimentos pertinentes, relevantes, socialmente comprometidos e rigorosos cientificamente. Não é suficiente gerar e ensinar conhecimentos ao acaso. É preciso que esses conhecimentos ajudem a melhorar a humanidade, tenham real significação às pessoas e contribuam efetivamente para o avanço e o desenvolvimento da ciência. Há relevância quando a instituição participa da vida social, em seus múltiplos aspectos econômicos, culturais, de saúde, de educação, transporte, lazer, especialmente quando a principal preocupação é com os grupos mais carentes.

Não são ações de mão única. Para ser realmente relevante e de qualidade social é preciso que se estabeleça um diálogo entre produtores e consumidores do conhecimento, que estão na instituição educativa e na população, uns aprendendo com os outros, em relação de dupla direção. Os compromissos institucionais precisam ultrapassar a oferta quase mecânica do ensino e da pesquisa. É preciso que a formação e os conhecimentos sejam um campo de luta contra as desigualdades, a pobreza, a fome, a insalubridade, o analfabetismo, as injustiças sociais, o desemprego, a deterioração ambiental, a violência, a cultura de paz, o diálogo intercultural, carência cultural, o atraso tecnológico.

A pertinência está relacionada com as necessidades concretas e mais urgentes da população. Minorar os agudos problemas sociais, solucionar alguns deles, não é tarefa isolada das instituições. O empenho deve ser conjuntamente das instituições, de setores da população e do Estado. Do ponto de vista da instituição educativa, além do envolvimento com as questões concretas e prementes, pertinência é a prática dum compromisso que visa cumprir um projeto ético-político da sociedade, de acordo com as finalidades essenciais traçadas pela instituição e segundo suas possibilidades e competências. São imprescindíveis as boas e adequadas estruturas materiais e humanas, a eficácia administrativa, o diálogo permanente, o 
protagonismo de professores e estudantes, a clareza da missão educativa, mas tudo isso deve estar em função da construção de uma cidadania pública da sociedade democrática.

Tudo isso tem um nome: responsabilidade social. Hoje vivemos uma grave crise civilizatória. Está se perdendo a capacidade de explicação racional do mundo. Prevalece uma grave crise de valores, com fortes manifestações de esgarçamentos do tecido social, da entronização do consumismo e do individualismo, da erosão da moral e da ética, da desvalorização da solidariedade e da capacidade de ver o outro, da obliteração da reflexão e da crítica. Um dos desafios mais importantes, irrecusáveis e urgentes, no quadro geral de anomia que grassa mundo afora, consiste em recuperar a capacidade e o hábito de refletir criticamente sobre os significados das ações e pensamentos e os destinos do mundo globalizado que os homens vêm construindo. Em termos gerais, os principais traços dessas transformações atuais seriam: "mentalidade pragmático-operacional, visão fragmentada da realidade, antropocentrismo relativizador, atomismo social, hedonismo, renúncia ao compromisso e desligamento institucional em todos os níveis: político-ideológico, religioso, familiar, etc." (FERNÁNDEZ DEL RIESGO, 1990, p. 89). Em palavras de Bauman: “questionar as premissas supostamente inquestionáveis do nosso modo de vida é provavelmente o serviço mais urgente que devemos prestar aos nossos companheiros humanos e a nós mesmos" (BAUMAN, 1999, p. 11). A educação superior tem enorme responsabilidade na construção de atitudes de constante questionamento e reflexão sobre as transformações voláteis e vertiginosas impulsionadas pela globalização. O que não se há de perder é a capacidade do olhar crítico sobre os destinos do homem no mundo. Assevera Ladrière (1978, p. 121): "Os elementos verdadeiramente unificadores, os valores mais fundamentais que sustentam, justificam e inspiram a todos os demais, dependem estreitamente das concepções relativas ao destino do homem".

Certamente "os intelectuais por si só não têm condição de mudar o mundo, embora nenhuma mudança desse tipo seja possível sem sua contribuição" (HOBSBAWM, 2013, p. 236). Por sua vez, Wallerstein (2005, p.59) aponta a direção a seguir: arranjar sistemas intelectuais de compreensão e transformação da realidade, desenvolvendo o pensamento crítico e analítico, construindo conhecimentos e aplicando técnicas, de acordo com as mais importantes prioridades da sociedade; avaliar moralmente as decisões e os rumos a seguir; avaliar politicamente os meios para atingir mais facilmente os fins. Isso significa, entre muitas outras interpretações, o que este texto vem afirmando. É papel fundamental da educação superior, não excluindo outros objetivos, produzir conhecimentos e fazer ciência com valor, relevância e pertinência sociais, sempre em íntima aliança com a busca permanente dos fins justos na vida moral e política. 
Por que trazer essas reflexões à Revista Avaliação? Em primeiro lugar, porque essa revista trata dos assuntos essenciais da educação superior. É urgente pôr como objeto de reflexão e questionamentos os conceitos vigentes na administração central, em setores da sociedade e, principalmente, nos campi universitários. Não por mero exercício acadêmico, mas porque os fenômenos concebidos e carregados por essas palavras não são nada neutros e indiferentes. O sequestro semântico dessas palavras produzido pela economia, amplamente prevalente, desviou o sentido que se lhes dava na educação. São universos diferentes de natureza, forma e finalidades. Uma segunda razão, ainda ligada à primeira, diz respeito à fragilização da pertinência ante a prevalência atual da qualidade, tal como gestada nos principais centros universitários, em conexão com as estruturas do poder político mundial, impulsionada pelas grandes corporações internacionais e emulada pelos seus correspondentes nacionais. Explicando melhor: os processos de avaliação e de acreditação seguem prioritariamente as metodologias impostas pelos centros do poder universitário, político e econômico, segundo os ditames das grandes corporações globalizadas. Aí se trata de uma qualidade de acordo com os critérios do mundo econômico, abstrata, genérica, quantitativista, e não propriamente da concepção de qualidade da educação como desenvolvimento pessoal, fortalecimento da cidadania, elevação cultural da população, promoção de equidade e da solidariedade, enriquecimento da identidade nacional, construção da Nação, enfim, formação humana plena, consistente, em todas as dimensões. A educação é essencialmente pública e social, portanto, deve instaurar-se como elevação humana e desenvolvimento da humanidade. O que é público não admite rivalidade. Ao contrário, pertence ao universo axiológico da solidariedade.

Os processos avaliativos importados, em larga escala, modelos universais emulados quase automaticamente nos sistemas universitários nacionais, embora não devam ser abolidos, uma vez que dão uma certa visão comparativa e sistêmica, precisam ser complementados, interpretados e até ultrapassados por processos autenticamente nacionais e institucionais, pois não dão conta de aprofundar o conhecimento e a crítica sobre cada unidade universitária em particular. Não conseguem mostrar a importância das práticas pedagógicas, científica, de inserção na comunidade, seja em termos de cumprimento adequado de sua missão, seja evidenciando falhas e fragilidades. Não alcançam compreender os sentidos da formação construída em uma instituição ou em um curso. Não conseguem dimensionar o valor das atividades no entorno social e muito menos induzir formas de participação nas diversas comunidades. Não possibilitam formar uma visão integrada do conjunto de atividades, nem mesmo correlacioná-lo com a missão institucional. 
Tudo isso leva a concluir ser imprescindível a autoavaliação, para além da avaliação externa: séria, participativa, democrática, dialógica, reflexiva, questionadora, quantitativa e densamente qualitativa, socialmente responsável, formativa e crítica.

\section{Referências}

BAUMAN, Zigmunt. Globalização: as consequências humanas. Rio de Janeiro: Zahar, 1999. DIAS SOBRINHO, José. Higher education: a public good, a State duty. In: WORLD CONFERENCE ON HIGHER EDUCATION: Public Responsability for Higher Education, 2009, Paris. Paris: UNESCO, 2009. Cap. 6. Disponível em: https://unesdoc.unesco.org/ark:/48223/pf0000183238?posInSet= 2\&queryId= N-EXPLORE9025fa37-5d21-49a6-b447-67b2d972305a

DIAS SOBRINHO, José. Cambios y reformas en la educación superior. In: BERNHEIM, Carlos Tünnermann (ed.). La educación superior en América Latina y el Caribe: diez años después de la Conferencia Mundial de 1998. Cali: Iesalc-Unesco, PUJ, 2008. Capítulo II.

FERNÁNDEZ DEL RIESGO, Manuel. La posmodernidad y la crisis de los valores religiosos. In: VATTIMO, Gianni et al. En torno a la posmodernidad. Barcelona: Editorial Anthropos, 1990.

FREITAG, Michel. Le naufrage de l'université et autres essais d'épistémologie politique. Québec: Éditions La Découverte, 1995.

HOBSBAWM, Eric. Tempos fraturados: cultura e sociedade no Século XX. São Paulo: Companhia das Letras, 2013.

LADRIÈRE, J. El reto de la racionalidad. Salamanca: Unesco-Sigueme, 1978.

MUÑOZ, Manuel Ramiro. Pertinencia y nuevos roles de la educación superior en la eegión. In: BERNHEIM, Carlos Tünnermann (ed.). La educación superior en América Latina y el Caribe: diez años después de la Conferencia Mundial de 1998. Cali: Iesalc-Unesco, PUJ, 2008 .

WALLERSTEIN, Immanuel. Un mundo incierto. Buenos Aires: Libros del Zorzal, 2005. 